\title{
Incursões de Clio na Terceira Margem do Ocidente: experiências de pesquisa sobre o ensino de história do Oriente em uma escola pública de Campina Grande -PB ${ }^{*}$
}

\author{
Incursions by Clio in Third Margin of the West: experiences of \\ research on teaching the history of the East in a public school of \\ Campina Grande-PB
}

\author{
Catarina de Oliveira Buriti** \\ José Otávio Aguiar****
}

\section{RESUMO}

Reconhecendo as dificuldades enfrentadas pelos professores de história que atuam nas escolas públicas estaduais de Campina Grande-PB, em abordar, em sala de aula, a história do chamado Oriente Distante, sobretudo pela escassez e pela pouca acessibilidade dos manuais didáticos dedicados ao tema em todo o território nacional, objetivamos, através deste trabalho, estabelecer parcerias entre a Unidade Acadêmica de História e Geografia e as escolas públicas do Ensino Médio de Campina Grande, para orientar a elaboração de estratégias de ensino de história do Japão, da China e da Índia. Para tanto, com base na realização de um diagnóstico sobre a ocorrência desses temas nos conteúdos programáticos das escolas, promovemos parcerias de pesquisa e elaboração de manuais didáticos acessíveis a alunos e professores do Ensino Médio do Colégio Estadual da Prata. Essa parceria foi realizada através de reuniões periódicas e da realização de oficinas temáticas com alunos e/ou professores a respeito dos conteúdos em pauta. A partir dessa pesquisa foi possível diagnosticar as dificuldades enfrentadas pelas escolas públicas para o ensino de temas específicos que ainda constam timidamente nos livros didáticos e que, em geral, requerem uma infraestrutura e uma formação complementar específica para os docentes.

PALAVRAS-CHAVE: História, Oriente Distante, Ensino, Metodologias.

\section{ABSTRACT}

Recognizing the difficulties faced by teachers of history in public schools that operate state of Campina Grande-PB, to deal in the classroom, the history of the so-called Far East, especially the shortage and poor accessibility of teaching materials devoted to the subject throughout the national territory, aimed, through this work to establish partnerships between the Academic Unit of History and Geography and the public schools of the High School of Campina Grande, to guide the development of strategies for teaching the history of Japan, China and India. Thus on the basis of a diagnosis on the recurrence of such themes in the content of school programs, promote partnerships in research and development of teaching materials available to students and teachers of the High School of the College of the Silver State. It was done through regular meetings and the holding of thematic workshops with students and/or teachers about the issues at stake. From this research it was possible to diagnose the difficulties faced by public schools to teach specific subjects that are still tentatively in textbooks and, in general, require an infrastructure and additional training for specific teachers.

KEYWORDS: History, Far East, Education, Methodologies.

\footnotetext{
A presente pesquisa foi desenvolvida com apoio do PIBIC/UFCG/CNPq.

** Bacharel em Comunicação Social pela Universidade Estadual da Paraíba (UEPB) e Mestranda em História pela Universidade Federal de Campina Grande (UFCG) / Brasil.

*** Doutor em História e Culturas Políticas pela Universidade Federal de Minas Gerais (UFMG), Pós-Doutorando em História pela Universidade Federal de Pernambuco (UFPE) e Professor da Universidade Federal de Campina Grande (UFCG) / Brasil.
} 
Faz parte da miséria do homem o não poder conhecer mais que fragmentos daquilo que já passou, mesmo no seu pequeno mundo; e faz parte da sua nobreza e da sua força o poder conjecturar para além daquilo que pode saber.

Alessandro Manzoni

\section{Introdução}

O título deste trabalho parafraseia o livro sobre os povos sul-americanos organizado por Adauto Novais, A outra Margem do Ocidente. Buscamos, assim, detectar o que seria, na ordem de expansão e incorporação a um universo novo de significações, uma terceira margem, e escolhemos como ponto de apoio aquelas três nacionalidades que ainda figuram de forma incipiente nos currículos nacionais de história, não obstante revestir-se de especial interesse para a atual geopolítica mundial: Japão, China e Índia. (NOVAIS, 1999).

O Oriente Distante exerceu uma enorme presença na formação da imagem que a Europa ocidental construiu a respeito de si mesma. Desde a Antigüidade, os contatos entre a China da rota da seda e o mundo clássico greco-romano, alimentavam curiosidades e ambições das mais variados matizes. A civilização helenística, um emaranhado de reinos e impérios espraiados entre a Índia e o Oriente Médio, divididos entre os antigos generais alexandrinos, havia conduzido a cultura grega até as margens do Ganges. Entretanto, foi entre os séculos XVI e XIX, que um esforço intelectual interpretativo construiu uma imagem do Oriente para uma nova Europa que se expandia pelo Atlântico, aventurava-se pelo Pacífico e adentrava o Índico, fundando entrepostos avançados de sua cultura naquelas que, na expressão etnocêntrica do historiador ambiental Alfred Crosby, seriam as neoeuropas.

Os contatos estreitos entre o Império Ultramarino Português e os mundos japonês, chinês e indiano, entre os séculos XV e XIX, têm sido objeto de interesse recente por parte de uma historiografia colonial partida de centros acadêmicos do Sudeste. Assim, avalia-se, historicamente, as repercussões comerciais, as influências lingüísticas, as aclimatações de espécies botânicas e animais e até uma quase diáfana presença da arte marcial dos chineses pobres plantadores de chá que vinham de Macau sobre os jogos que, antes se cria, tão exclusivamente afro-brasileiros, da Capoeira. 
O crescimento do potencial de consumo das populações da China e da Índia no mercado internacional, a destruição dos ambientes naturais desses dois países, resultante do modelo de expansão por eles adotado, a postura do Japão pós-1970 em relação às políticas ambientais, o controle das emissões de $\mathrm{CO}_{2}$ e a legislação asiática em relação à destruição da camada de ozônio e ao aquecimento global, têm sido temas constantes dos noticiários, ocupando também, a ordem do dia entre as discussões dos cursos e colóquios de Relações Internacionais. Não obstante este fato, constatamos uma quase ausência destes conteúdos nos manuais didáticos de história em todo o território nacional, particularmente no que se refere aos conteúdos programáticos de história do Ensino Médio estadual na cidade de Campina Grande-PB.

O interesse contemporâneo de nossa sociedade pelos grandes países asiáticos como a China, a Índia e o Japão, no momento em que estes despontam como potências no cenário mundial, instigou-nos a refletir sobre a forma como os temas relacionados à história do Oriente são abordados no âmbito dos cursos de graduação em história das universidades brasileiras e, especialmente, nos currículos de história dos níveis de Ensino Fundamental e Médio. Vale lembrar que essa atenção ao papel do Oriente Distante em nossa sociedade, parte, em grande medida, de um aumento da exposição de atualidades econômicas e culturais a respeito desses países nas mídias escrita, televisiva e, particularmente, no cinema, onde temas relativos a essas culturas milenares têm ocupado papel de destaque nos últimos anos.

Como já nos lembrava Marc Bloch em seu Metier D’ Historian, a história é sempre filha do seu tempo, lança ao passado interrogações que partem de inquietações de nosso presente, e, nesse contexto, situamo-nos como historiadores preocupados em contribuir para atender a essa demanda por pesquisas e material didático, originada dessa ampla veiculação diária de informações sobre a cultura oriental, com o intuito de contribuir para o conhecimento de parte de sua história em nossa sociedade.

Entre os motivos que podem levar a esse vácuo de estudos orientais nas universidades brasileiras, podemos elencar: a dificuldade de acesso às fontes e as restrições em relação à língua, considerando que poucos eruditos têm fluência em idiomas asiáticos, como o mandarim, o hindi, o grego antigo e mesmo línguas já desaparecidas como o sânscrito e o aramaico. Encontraremos 
esses eruditos apenas em grandes colleges ingleses ou em renomadas universidades francesas. A dificuldade no domínio das variadas línguas asiáticas se coloca como o primeiro grande obstáculo, embora existam obras traduzidas para o português (não muitas, é verdade), como também livros em línguas mais acessíveis para o estudioso brasileiro, como o inglês e o francês. Um segundo obstáculo diz respeito ao grande distanciamento geográfico e cultural existente entre o Brasil e o chamado Oriente, o que leva a um profundo desinteresse pelos temas de estudos asiáticos. Ao mesmo tempo em que existem temas mais próximos de nossa realidade, como história da Europa, do Brasil e da África, assuntos históricos mais distanciados, como a Ásia e os países do Leste europeu, por exemplo, deixam de ter a devida atenção. Ademais, outra dificuldade que pode ser apontada se refere ao fato de que, ao lidarmos com sociedades muito diferentes da nossa, em geral, tendemos a lançar um olhar etnocêntrico, de estranheza e, ao mesmo tempo, de superioridade que nos impede de vê-las sob a ótica de suas especialidades histórico-culturais.

Tendo em vista concretizar uma política de incentivo às iniciativas de pesquisa e extensão, incentivada há alguns anos pela nossa instituição, de modo que venham a suprir certa carência de experiências didático-pedagógicas e de novas metodologias elaboradas para a melhoria do ensino de história, buscamos avançar para além dos limites dos muros universitários, procurando estender às escolas estaduais e particulares com as quais estabelecemos parcerias, experiências e projetos que visam dialogar com os livros didáticos, as políticas educacionais, a inclusão ou exclusão de certos conteúdos programáticos, etc.

A partir do diálogo com os professores de história da Escola Estadual da Prata foi possível perceber que a ausência de referências mais atentas aos temas relacionados à história do Oriente nos cursos de Ensino Médio, em Campina Grande-PB, não se deve, em absoluto, à sua irrelevância histórica e geopolítica, mas, primordialmente, à falta de material didático acessível e de conhecimentos a respeito por parte dos professores.

Nesse cenário, com base no diagnóstico sobre a ocorrência de temas de história oriental nos conteúdos programáticos, objetivamos, neste trabalho, identificar quais são os desafios e as alternativas possíveis de serem viabilizadas para permitirem um ensino de história do Oriente mais prazeroso e agradável. Trata-se do relato de uma experiência de pesquisa realizada em uma das escolas 
estaduais da cidade, através da qual problematizamos temas como: os livros didáticos, as lacunas neles evidenciadas no tocante a essa temática e as estratégias criativas empreendidas pelos professores para elaborarem seus métodos didáticos; a infra-estrutura escolar, ou a sua ausência ou incompletude, dadas as dificuldades que o ensino público enfrenta; a escassa bibliografia traduzida sobre o tema e as dificuldades de acesso dos professores do ensino básico a esse material.

Buscamos contribuir para o debate após constatarmos o quanto esse acesso era restrito a esses profissionais, produzindo sínteses didáticas que traduzissem a bibliografia disponível em idioma estrangeiro -o fizemos mais frequentemente a partir do Inglês e do Francês- ou tornassem mais acessíveis informações constantes em publicações que circulavam esparsamente no território nacional. A cidade de Campina Grande é mal servida de livrarias e o acervo bibliográfico de ciências humanas da Universidade Federal de Campina Grande (UFCG) - uma universidade cujos campos tradicionais de investimento e desenvolvimento acadêmico são ligados aos cursos tecnológicos- é muito deficitário. Dessa experiência nasceu o livro Entre o Kati e o Nirvana: Budismo, arte marcial e ascese em uma breve história das técnicas marciais do mosteiro de Shaolin (Séculos XVI a XIX), publicado pela EDUFCG, em 2008. Nele, conta-se a história da arte marcial chinesa, procurando relacioná-la ao desenvolvimento da religiosidade Chan-Zen a enventos políticos ligados ao imperialismo europeu na Ásia, como as Guerras dos Boxers e do Ópio. ${ }^{1}$ A maior parte da bibliografia sobre o tema encontra-se, ainda, em idioma estrangeiro, e, parte do trabalho do livro foi produzir uma síntese didática dos debates historiográficos em países como os Estados Unidos, a França e Israel. Mesmo o que se tem em idioma português, obra frequente de impressão de editoras lusitanas, raramente é veiculado e popularizado no Brasil. O ponto alto foi representado pela experimentação em oficinas, através das quais foi possível elaborar recursos didáticos para o ensino história do Oriente Distante através da troca de experiências entre professores e alunos das instituições envolvidas, quais sejam, alunos e professores da escola pública e do curso de história da UFCG. O cinema das artes marciais e sua história, as representações idealizadas da China na obra

\footnotetext{
1 AGUIAR, José Otávio. Entre o Kati e o Nirvana: Budismo, arte marcial e ascese em uma breve história das técnicas marciais do mosteiro de Shaolin (Séculos XVI a XIX). Campina Grande, PB: EDUFCG, 2008.
} 
de Voltaire, a obra O Orientalismo de Edward Said, foram alguns dos temas de artigos didáticos produzidos como sínteses introdutórias e publicados sob o título Série Textos Didáticos - História do Oriente. ${ }^{2}$

\section{Ensino de História: embates, dilaceramentos e perspectivas}

Há algumas décadas, a relação entre a formação do professor de história e o cotidiano da sala de aula tem sido pauta de muitas discussões em torno das quais, comumente, ressalta-se a necessidade de realização de mudanças com o objetivo de se superar o ensino tradicional de história. Embora esforços tenham sido despedidos nesse sentido, no que se refere à prática cotidiana do professor de Ensino Fundamental e Médio, de um modo geral, as mudanças ainda não são satisfatórias. Na realidade, podemos afirmar que o quadro-negro, ao lado do livro didático, ainda persiste na educação brasileira, muitas vezes como único recurso na formação do professor e na sua atuação em sala de aula. E é nesse contexto que podemos ressaltar profundos dilaceramentos e embates que permeiam a prática cotidiana do professor e que não lhe permite integrar todos os tipos de saberes adquiridos em sua formação com um saber-fazer numa prática profissional mais prazerosa e conseqüente.

Espera-se do professor que represente a união entre a competência acadêmica (domínio dos saberes) e a competência pedagógica (domínio da transmissão do saber), aliando competências, convicções e experiências de vida. No entanto, a formação do professor de história -assim como de tantos outrosde Ensino Fundamental e Médio, em geral, limita-se ao curso de graduação. Uma vez formado, esse professor envolve-se com encargos familiares, com a luta pela sobrevivência e quase sempre não dispõe de tempo nem de dinheiro para investir em sua qualificação profissional. Seu cotidiano é preenchido por múltiplas tarefas; seu tempo de viver é fragmentado, dilacerado pelas preocupações, muitas vezes contraditórias, entre sua profissão, sua família e seu progresso cultural.

Os dilaceramentos atingem também os alunos na sua condição de receptáculos de informações, conteúdos, currículos, livros e materiais didáticos,

2 AGUIAR, José Otávio. (Org.) Série Textos Didáticos - História do Oriente. Campina Grande, PB: EDUFCG, 2008. 
na maioria das vezes desinteressantes, que eles lutam por decifrar e entender. Daí o fato de freqüentemente se escutar o ressoar de suas queixas, revoltas, apatias e embates, além da recusa e contestação que manifestam a insegurança e o temor ante os instrumentos de poder aos quais são submetidos, como exames e julgamentos dos colegas e professores (SCHMIDT, 1998: 56).

Outra questão considerada fundamental e imprescindível ao ensino de história na atualidade e que se impõe como um desafio a ser enfrentado pelos educadores na sala de aula diz respeito à realização da transposição didática ${ }^{3}$ dos conteúdos, do procedimento histórico e também da relação entre as inovações tecnológicas e o ensino de história.

A partir da segunda metade do século XX, a sociedade contemporânea produziu um aumento substancial de informações e de tecnologias usadas em sua gestão. Passamos a viver em uma sociedade altamente informatizada, onde a apreensão da linguagem imagética é uma necessidade, em que a velocidade e o volume de informações são cada vez maiores e mais ágeis devido às novas tecnologias comunicacionais que permeiam a realidade e o cotidiano tanto de professores quanto de alunos. Constata-se a presença, direta ou indiretamente, na escola e na sala de aula, de um conjunto de novas tecnologias de informação e comunicação de caráter bastante diversificado -desde jornais, revistas, desenhos, televisão, vídeo, etc. até o computador e a internet que pode sintetizar todos eles.

A possibilidade de uso das tecnologias da informação e comunicação como contribuição para a relação ensino-aprendizagem e, particularmente, como contribuição para um salto qualitativo nos novos (e velhos) problemas pertinentes ao ensino de história, tem suscitado posições bastante contraditórias. De um lado, certo sentimento de repulsa em relação à utilização desses meios na prática pedagógica e, por outro lado, quando acolhidas pelos educadores, tais inovações tecnológicas têm sido usadas normalmente como técnicas de ensino, estratégias para preencher ausências de professores ou como recursos para tornar as aulas menos enfadonhas. Trata-se de adequações

3 A noção ou o conceito de transposição didática ou de recomposição didática permite pensar a transformação de um saber dito científico em um saber a ensinar, tal qual aparece nos programas, manuais, na palavra do professor, considerados não somente científicos. Designa o processo de transformação científica, didática social, que afeta os objetos de conhecimento até a sua tradução no campo escolar. 
superficiais, na medida em que a inovação se constitui não em um produto, mas em um processo e em uma maneira de ser e estar na educação.

Diversos estudos e pesquisas atuais apontam para a necessidade de um redimensionamento de tais práticas, em direção à priorização de reflexões acerca das especificidades e das linguagens próprias dos meios de comunicação.

Questionando-se acerca da possibilidade de o ensino apreender, em seus conteúdos e métodos, as transformações tecnológicas ocorridas que suscitaram novas representações e práticas sociais, e estabeleceram uma nova relação do grande público com o conhecimento e o imaginário coletivo, constata-se que, neste processo, não basta ater-se às características e potencialidades próprias dessas novas tecnologias, mas, também, de refletir e retomar a sua interação com os currículos e com a prática pedagógica em sua totalidade. (Ibidem: 56).

Nesse contexto, é possível perceber que a interação destes novos meios didáticos no currículo poderá conduzir a mudanças mais ou menos profundas no processo educativo, desde o planejamento e a definição das finalidades educacionais, envolvendo também metodologias, estratégias e atividades a implementar, até os processos de avaliação e os equipamentos escolares necessários.

Existe atualmente uma produção significativa e bastante interessante acerca da utilização de outras linguagens na escola. Diversos trabalhos têm sido realizados com o objetivo de estudar e propor alternativas para as atividades escolares a partir das linguagens dos meios de comunicação e das novas tecnologias. (NAPOLITANO, 2005).

Foi com base nessa perspectiva que através da realização desta pesquisa nos propomos experienciar para, posteriormente, apontar novas alternativas que possam contribuir para a superação de algumas das dificuldades inerentes à prática docente, especialmente quando se trata de ensinar história para alunos do nível médio de escolas da rede pública, nas quais os desafios são ainda maiores.

Algumas considerações devem ser apresentadas a respeito da definição do percurso teórico-metodológico que nos propomos seguir:

Uma primeira questão a ser destacada diz respeito ao fato de que o livro didático tem sido, desde o século XIX, -e ainda permanece nos dias atuais- o principal instrumento de trabalho de professores e alunos, sendo utilizado nas 
mais variadas salas de aula e condições pedagógicas. Nesse contexto, levando em consideração também o fato de que a equipe de profissionais responsáveis pela colocação desse instrumento no mercado tem dado uma abordagem muito restrita e simplista em relação às sociedades orientais, pretendemos com este trabalho refletir sobre a elaboração e a utilização de propostas didáticas que tratam exclusivamente de temáticas relativas à cultura e ao modo de vida dos povos e das sociedades do Oriente, como uma possibilidade didática para o ensino de história em escolas públicas do Ensino Médio do município de Campina Grande e como forma de contribuir para o preenchimento das lacunas geralmente deixadas pelos manuais escolares.

\section{História e Historiografia do Oriente Distante}

O diálogo entre a historiografia francesa e o Oriente Distante é tão antigo quanto a Revolução Historiográfica que deu origem à chamada École des Annales. Destacamos, aqui, as contribuições de Marcel Granet (1884-1940), sociólogo, sinólogo e historiador francês que despontou como colaborador de primeira hora na obra de Marc Bloch e que foi autor dos até hoje essenciais $O$ Pensamento Chinês e A Civilização Chinesa. ${ }^{4}$ Pretende-se, aqui, enfocar a contribuição de Granet e de seus colaboradores para a formação de um grupo de sinólogos no âmbito dos estudos que envolveram a formulação da proposta historiográfica dos Annales. Percebe-se que, acompanhando a influência desses sinólogos na obra de autores como Fernand Braudel, é possível estabelecer relações que toquem a gênese do conceito de Economia-Mundo. Nesse sentido, abordar-se-á também, em seguida, as contribuições braudelianas para o estudo da civilização material, da economia e do capitalismo, entre os séculos XV e XVIII, no que toca às sociedades do Oriente e às suas influências sobre o Ocidente.

O estudo da história e da mentalidade chinesas foi realizado de forma pioneira no Ocidente por Granet, quem, em 1904, ingressou na École Normale Superiéure. Discípulo de Durkheim, interessado pelos estudos sobre o

\footnotetext{
4 Ambos contam com traduções brasileiras, embora, o último, editado pela Editora Brasiliense na década dos anos de 1970, já seja edição esgotada: Cf. GRANET, Marcel. O Pensamento Chinês. São Paulo: Cia das Letras, 1998; GRANET, Marcel. A civilização Chinesa. São Paulo: Brasiliense, 1979.
} 
feudalismo, parte para a China onde estudou o sistema feudal chinês introduzindo o método sociológico na sinologia moderna. De volta à França, torna-se o diretor dos estudos sobre as religiões do Extremo Oriente na École Pratique des Hautes Études, professor na Escola Nacional de Línguas Orientais Vivas e Co-fundador do Institute des Hautes Études Chinoise.

Entre suas principais obras, podem ser destacadas: La religion des Chinois (1922), La civilisation Chinoise (1929) e La Penseé Chinoise (1934). A análise das obras de Granet leva-nos a perceber que o mesmo antecede em décadas as inovações trazidas pela Escola dos (Analles)Annales, a partir de 1929, pelos fundadores Marc Bloch e Lucien Febvre, entre elas, a tentativa de escritura de uma história das mentalidades.

A originalidade das obras de Granet constitui-se em não se limitar apenas à descrição dos fatos -tão em evidência na época que precede o movimento dos Annales. Embora sejam, evidentemente, indispensáveis, Granet percebeu que eram insuficientes para fazer "compreender" uma civilização. Daí a sua preocupação em tentar revelar os estados de espírito e a mentalidade dos camponeses do período feudal chinês. Assim como os fundadores dos Annales viriam propor, posteriormente, no ambiente de Estrasburgo, a elaboração de uma história crítica e que dialogasse com outros campos de saber como a etnologia, antropologia, geografia, psicologia, etc, propunha-se inaugurar uma história crítica da China, ao criticar os ocidentais por contar a história dessa sociedade sem assinalar o seu caráter dogmático e por não se esforçarem em assumir uma atitude crítica de distinguir, nas tradições, o verdadeiro e o falso. (GRANET, 1979).

Segundo Granet, os documentos sobre a China não revelavam o menor dos fatos históricos e não permitiam descrever o lado material da civilização chinesa. Ignoravam os pormenores das guerras e das intrigas políticas, os usos administrativos, as práticas econômicas, o modo de vestir, etc., mas em troca possuíam inúmeros testemunhos preciosos sobre as diversas atitudes sentimentais ou teóricas que foram adotadas na China, em meios diferentes, a respeito do costume, da riqueza, da arte administrativa, da política ou da guerra.

Marcel Granet, em $A$ Civilização Chinesa afirma que não é possível aprofundar-se no conhecimento da China se limitasse sua tarefa a definir um conjunto de atitudes que caracteriza o sistema social dos chineses da 
Antigüidade. Essa obra se depara com "A China Antiga na época dos Han”, buscando encontrar as grandes linhas da evolução política que conduz à criação do império chinês, de maneira bastante audaciosa, apropriando-se de narrativas extraídas de epopéias, de romances ou de poemas históricos. Aqui, mais uma vez, vemos semelhanças com os estudos realizados pelos pioneiros do movimento dos Annales, especialmente Febvre, que toma uma obra literária como fonte, Gargantua e Pantagruel, de Rabelais, para estudar as mentalidades dos renascentistas, o que era bastante inusitado para uma época em que o que predominava era a tradição erudita.

Para além de escrever a história de um Estado, ou mesmo de um povo, Granet pretendia escrever a história da China como a de uma civilização ou, antes, a de uma tradição de cultura. Seu interesse principal seria talvez, mostrar como a idéia de civilização pôde, numa história tão longa, realçar de maneira quase contínua, a idéia de Estado. Mas, além de dar sua contribuição à história política, ele também enfatiza aspectos da história da sociedade chinesa e, principalmente, do pensamento e da mentalidade dos chineses. Defende que é provável que a civilização chinesa date de uma antigüidade remota; é possível que sua história apresente mesmo uma continuidade e pode ser que a China possa ter possuído, muito antigamente, uma espécie de homogeneidade.

A historiografia tradicional chinesa defende que a sociedade tenha sido perfeita desde a origem, no tempo em que os fundadores da civilização tradicional manifestavam sua Santidade. A idéia de que o príncipe, apenas pelo cumprimento dos ritos, consegue governar os costumes e policiar o mundo, corresponde a um ideal que, sem dúvida, não seria uma invenção recente. No entanto, percebe-se que se trata de um ideal purificado: seria desejável, por isto, conhecer profundamente sua formação e sua história. Para a doutrina ortodoxa, este ideal seria um dado, um fato importante. (Ibidem, 1979: 229).

Aspectos relevantes da vida dos camponeses da China feudal são ressaltados em A Civilização Chinesa, na qual Granet apresenta o modo de vida, costumes, organização social do trabalho, comportamentos, ritos, hábitos alimentares e formas de pensamento, as tradições, os mitos e tabus presentes naquela sociedade. Através da análise das diversas temáticas e aspectos da vida social abordados por este sinólogo, já é possível perceber algumas das idéias que viriam a ser defendidas pelos Annales, movimento que combateria a história 
reducionista e que privilegiava os "figurões" ou grandes personalidades da política e os assuntos diplomáticos, o que era típico de certa tradição historiográfica privilegiada até sua emergência.

Também atentou para a forma como os chineses realizavam a divisão do trabalho, destacou o papel que as mulheres desempenhavam na economia daquela sociedade: os primeiros campos eram reservados às plantas têxteis. Ali era o domínio das mulheres, das tecelãs. Os tecidos que produziam cânhamo ou seda, constituíam a principal riqueza de moeda. Abaixo estavam as culturas masculinas, principalmente os campos destinados aos legumes secos, depois os campos de cereais e, mais tarde, os quadrados de terra reservados ao arroz. Havia na China uma tendência atual à especialização de culturas por regiões apropriadas. Nos tempos antigos, cada cantão procurava produzir tudo a fim de que a subsistência do grupo fosse assegurada. Para dirigir bem essas diversas culturas, era necessário praticar a divisão do trabalho e adotar uma espécie de nomadismo limitado. As tecelãs nunca deixavam a aldeia e seus pomares, mas os lavradores deviam passar todos os dias úteis nos campos de cereais. Tinham cabanas onde dormiam, fiscalizando constantemente suas colheitas. Do alvorecer à tarde, eles trabalhavam duramente. $\mathrm{O}$ único momento bom era o das refeições. Crianças e mulheres traziam-nas em cestas e eles comiam fazendo festas a suas esposas (Ibidem).

Aqui se percebe a contribuição do famoso sinólogo francês no que se refere ao estudo das relações de trabalho, da economia, ao cotidiano das populações camponesas da China feudal e, ao longo de toda sua obra, também são encontradas referências às práticas sexuais desses povos, fato que destaca a forma como esse autor inova as temáticas ao estudar a sociedade chinesa, abordando as multidimensões da vida social. Fato que evidencia a influência de Granet no âmbito dos estudos que envolveram a formulação da proposta historiográfica dos Annales.

Mas, para além dessas abordagens, deve-se destacar ainda os mitos, tabus, concepções do sagrado, emoções, filosofia, gestos, hábitos e costumes representados e interiorizados pela sociedade chinesa. Entre eles, ressalta-se as grandes festas populares realizadas a tempos regulares para devolver a alegria de viver aos camponeses cansados dos "duros labores cotidianos" e daquela "vida monótona e dura”. (Ibidem: 259-260). 
Instituições sociais como a família e o casamento também foram temas abordados pela historiografia francesa da época sobre a China. Nos tempos feudais, este seria considerado como um dos emblemas de acordos políticos, devendo não só aproximar os sexos opostos como famílias diferentes.

Obervamos que Granet dedicou boa parte de sua existência ao estudo e compreensão das fontes eruditas chinesas. Entretanto, não obstante sua capacidade de síntese e atenção às fontes (AGUIAR, 2008), atenta para a não ocorrência reservada em sua obra, de um papel especial para as artes marciais no universo de representações e mesmo no esquema de transmissão cultural daquela sociedade. Seu mais famoso livro, um best seller cuja primeira edição veio à luz em 1934, O Pensamento Chinês, lança-se à empreitada de compreender um pensamento que, ao contrário das principais matrizes grecoromanas ocidentais, não opõe sujeito e objeto, estabelecendo, antes, relações íntimas entre ambos, dentro de uma rede de significações que prevê uma certeza e um sentimento intrínseco da unidade do mundo. (GRANET, 1979)

Considerando o papel essencial desempenhado pela arte marcial na sociedade chinesa clássica, por ser a partir dela que boa parte dos códigos sociais e culturais foi veiculada, e, recentemente, tendo constatado relativa ausência de bibliografia a respeito desse tema, bem como, a lacuna didática nos cursos de graduação em história, Aguiar decidiu "dedicar uma pequena brochura à história da Arte Marcial Chinesa", na obra Entre o Kati e o Nirvana: budismo, arte marcial e ascese em uma breve história das técnicas marciais do Mosteiro de Shaolin (Séculos XVI a XIX) (2008: 5).

Concentrando-se, especificamente, no Mosteiro de Shaolin e nas técnicas marciais que, conforme transmitido pela tradição oral e confirmado por uma historiografia recente, parecem lá terem-se originado ou sistematizado, o autor estabelece uma síntese da historiografia que abordou o tema, debate a relação entre marcialidade e budismo e, ainda, explicita aspectos que concernem às características específicas da arte marcial chinesa.

No que tange à relação entre artes marciais e budismo, Aguiar (2008) ressalta o trabalho de Meir Shahar, historiador israelense que mais se dedicou ao estudo da história das artes marciais de Shaolin e o primeiro no meio acadêmico ocidental a produzir trabalhos sobre a relação entre marcialidade e religião budista no mosteiro. Shahar localiza nos séculos XVI e XVII as 
primeiras evidências da existência de uma marcialidade organizada no mosteiro. Neste período, um grande número de oficiais, artistas marciais e interessados viajavam para o templo para estudarem com os monges as técnicas das artes marciais.

Sintetizando a polêmica historiográfica em torno da ligação entre a origem das artes marciais chinesas e o taoísmo, Rodrigo Wolf Apollloni (2004), pesquisador da história da apropriação das técnicas da arte marcial chinesa no Brasil, salienta que os estudiosos se interrogaram sobre o momento em que religiosos chineses, a princípio taoístas e, posteriormente, budistas, passaram a incluir as artes marciais como elemento de sua rotina religiosa, ou, até, como parece por vezes ser em Shaolin, elemento de sua ascese religiosa. 5

Aguiar (2008) constata, por fim, que, para além de sua inserção numa lógica de estado e eficiência bélica, já, em grande medida, esvaziada, em função dos avanços tecnológicos dos últimos duzentos anos, as artes marciais chinesas sobreviveram por seu conteúdo ideológico e mítico, articulado de forma íntima e inseparável, aos valores constituintes da noção de tradição e nacionalidade chinesa.

Fernand Braudel, a partir de uma pesquisa de ampla erudição e abrangência, e com uma visão bastante original, destaca um papel importante para as sociedades do Oriente no que se refere ao desenvolvimento capitalista do Ocidente, ressaltando que, não obstante a Europa reclame para si o pioneirismo científico e tecnológico, muitos elementos presentes em sua sociedade e economia foram herdados das sociedades orientais (BRAUDEL, 1996).

Para Braudel, o capitalismo, a cada momento da sua história, apresenta-se como uma soma de meios, de instrumentos, de práticas, de hábitos de pensamento que são incontestavelmente bens culturais e que, como tais, viajam e são trocados. Mediante difusão cultural, o Ocidente herdou diversos meios e práticas comerciais das economias-mundo do Oriente, que viriam propiciar as bases para o desenvolvimento do capitalismo europeu. Entre essas heranças, podem ser citadas as letras de câmbio herdadas do modelo islâmico a partir do contato de mercadores italianos que muito cedo freqüentaram os portos e mercados do Islã (Ibidem).

5 Cf. DERRICKSON, Carol. M. Chinese for the Martial Arts. $1^{\mathrm{a}}$ edição. Rutland: Charles E. Tuttle, 1996. Veja-se também: HUNT, Leon. Kung Fu Cult Masters - From Bruce Lee to Crouching Tiger. Londres, New York: Wallflower Press, 2003. 
Aceitar a realidade das inúmeras dádivas do Oriente à Europa significa renunciar ao Ocidente dos historiadores tradicionais, um ocidente totalmente inventado por si próprio, genialmente, que trilha sozinho, progressivamente, as vias da racionalidade técnica e científica; significa não reconhecer aos italianos das cidades medievais o mérito da descoberta dos instrumentos da vida comercial moderna. Também tomar posição contra o papel matricial do Império Romano pelo fato de que estava ligado a uma vasta zona de circulação e de troca traçada pelos homens durante séculos, de um extremo a outro do mundo, uma economia-mundo (Ibidem).

Os países submetidos pela conquista muçulmana tinham um papel ativo nos tráficos do Oriente e do Mediterrâneo antes da chegada do conquistador; voltarão a tê-lo assim que os hábitos retomarem seus direitos. Aquilo que se costuma denominar de economia muçulmana é a execução de um sistema herdado, uma corrida de revezamento entre mercadores da Espanha, do Magrebe, do Egito, da Síria, da Mesopotâmia, do Irã, da Abissínia, do Gujarate, da Costa do Malabar, da China, da Insulíndia, etc. É em torno desses espaços que a vida muçulmana encontra por si só seus centros de gravidade, seus sucessivos "pólos": Meca, Damasco, Bagdá, Cairo -impondo-se a escolha entre Bagdá e o Cairo, conforme a rota para o Extremo Oriente utiliza o Golfo Pérsico, a partir de Basra e Saraf, ou o Mar Vermelho a partir de Suez e Djeda, o porto de Meca. Antes mesmo de existir, o Islã era, graças às suas heranças, uma civilização comercial. Os mercadores muçulmanos usufruíram, pelo menos junto dos mestres da política, de uma consideração precoce de que a Europa, por sua vez, será bastante avara. Essa imagem do Islã com seus mercadores expandindo a economia de trocas e negociações é uma imagem antecipada da evolução futura da Europa mercantil. O comércio de longa distância do primeiro capitalismo europeu, a partir das cidades italianas não deriva do Império romano. Sucede aos esplendores islâmicos dos séculos XI-XII, do islã que viu nascer tantas indústrias e produções para exportação, tantas economias de raio amplo. As navegações de longo curso, as caravanas regulares implicam um capitalismo ativo e eficaz. Por todo o Islã há corporações, e as alterações que elas sofrem (ascensão dos mestres, trabalho domiciliar, trabalho fora das cidades) lembram muitas das situações que a Europa conhecerá para que não haja uma lógica econômica na sua base. Nesse sentido, pode-se afirmar que 
aquilo que o capitalismo ocidental possa ter sido um bem de importação é sem dúvida alguma de origem islâmica (Ibidem).

Mas, o conceito de economia mundo faz com que se perceba que tal como na Europa, o resto do mundo é, há séculos, obcecado pelas necessidades de produzir, pelas obrigações da troca, pelas precipitações da moeda, sinais que já prenunciem ou denunciem certo capitalismo.

Norman Jacobs, em sua obra The Origin of Modern Capitalism and Eastern Asia, publicada em 1958, argumentou que o Extremo-Oriente só o Japão é hoje capitalista. Dizer que o capitalismo industrial foi ali mera imitação da industrialização européia não é explicação suficiente. Pois, nesse caso, seria questionar o porquê dos outros países do Extremo-Oriente foram e são incapazes, por sua vez, de reproduzir o modelo. É provável que haja estruturas antigas responsáveis por tal aptidão ou não-aptidão para acolher o capitalismo. Caberia assim ao pré-capitalismo dar a resposta, ao passado explicar o ponto de chegada. Com esse intuito, é importante comparar o antigo Japão com a China, culturalmente próxima, porém muito diferente; e com a Europa, que, culturalmente, está muito longe do Japão, mas talvez tenha certas semelhanças com ele. E, se é a sociedade, a organização social, o aparelho político -e não a cultura- que representam a dissemelhança entre o Japão e a China, a semelhança entre o Japão e a Europa assume uma dimensão significativa. Por esse processo, talvez se possa ter sobre o capitalismo em geral e sobre as suas origens sociais, esclarecimentos bastante novos (Ibidem).

Jacobs não hesita em colocar todo o passado da China e do Japão, o que se considera aprovado, de uma forma muito parcial, pelo fato de também isso ter sido relativamente feito em relação à Europa, remontando à ruptura do século XI e mesmo mais além dessa inflexão decisiva. $\mathrm{O}$ autor mencionado reduz os pressupostos do capitalismo a uma evolução multissecular de longuíssima duração, sendo à acumulação de provas históricas que ele deixa o cuidado de dirimir o problema levantado. Invoca, portanto, acerca de séculos e séculos, as diversas atividades funcionais das sociedades, das economias, das políticas governamentais, dos organismos religiosos. Tudo será abordado: as trocas, a propriedade, a autoridade política, a divisão do trabalho, a estratificação e a mobilidade sociais, o parentesco, os sistemas de herança, o lugar da vida religiosa - sendo o problema verificar todas às vezes o que, nessas 
permanências, se assemelha mais ao passado europeu e se revela portanto, em princípio, portador de um futuro capitalista (Ibidem).

Na China, o obstáculo é o Estado, a coesão de sua burocracia e pode-se acrescentar a longevidade desse Estado que decerto fica desarticulado por longos intervalos, mas se reconstitui sempre igual a si próprio: centralizador, moralizador também, agindo rigorosamente segundo uma moral confuciana freqüentemente atualizada, mas de modo geral fiel a princípios diretores que põem a seu serviço cultura, ideologia, religião(;) e o próprio Estado, isto é, os mandarins de todos os escalões, a serviço do bem comum (Ibidem).

Em tal sistema, a acumulação só é possível ao aparelho de Estado. Finalmente, a China terá vivido sob certo regime "totalitário" (se retirarmos da palavra o sentido odioso que recentemente adquiriu). E, a dado momento, seu exemplo vem apoiar nossa obstinação em distinguir fortemente economia e capitalismo. Pois a China tem uma sólida economia de mercado cuja base reside nas trocas muito ativas e volumosas, favorecidas por um governo para quem os bons resultados agrícolas são o essencial; mas, acima, a tutela onipresente do aparelho de Estado -e sua nítida hostilidade contra qualquer indivíduo que enriqueça “anormalmente” (Ibidem).

No Japão, os dados de um futuro capitalista estão lançados já na época Ashikaga (1368-1573), com a instauração de forças econômicas e sociais independentes do Estado (quer se trate das corporações, do comércio de longa distância, das cidades livres, dos mercadores associados que em geral não têm de prestar contas a ninguém). Os primeiros sinais dessa relativa falta de autoridade estatal aparecem mesmo mais cedo, assim que se instala um sistema feudal sólido. Com uma anarquia que lembra a da Idade Média européia, tudo cresceu ao mesmo tempo no cenário diversificado do Japão durante os séculos de sua lenta formação: o governo central, os senhores feudais, as cidades, os camponeses, os artesãos, os mercadores. A sociedade japonesa ficou enredada em liberdades análogas às da Europa, liberdades que são outros tantos privilégios atrás dos quais se enclausuram, se defendem, sobrevivem. Os senhores feudais foram, portanto, domados, mas seus feudos subsistiram, intactos. $\mathrm{O}$ xógum procede a confiscos e a família, mas também à redistribuição dos feudos. E as famílias feudais se multiplicarão assim até a época atual -belo teste de longevidade. 
Yao (2004) fornece-nos importantes subsídios para problematizarmos a relação que se estabelece, inversamente, entre a Europa e as sociedades orientais. Segundo ele, a presença do cristianismo na China, teve início com os nestorianos, já no século VII, e com missionários católicos, em Pequim, capital da dinastia mongol Yuan (1269-1368). Entretanto, foi somente a partir do final do século XVI, com a chegada dos jesuítas à China, que passou a ocorrer um sério diálogo entre a cultura ocidental e esta civilização, marcando o início de uma nova Era em que tradições cristãs e chinesas se misturavam numa interação que teria impacto significativo na vida religiosa e cultural dessas sociedades. Muitos desses missionários mergulharam no estudo da língua chinesa, dos antigos clássicos e dos costumes locais, adotando uma estratégia de acomodação, adaptando os seus sermões à cultura local e concentrando a atenção nos confucianos de elevado nível educacional.

Na maioria, os primeiros missionários cristãos a desembarcaram no sul da China, em fins do século XVI, eram homens notavelmente cultos e que impressionaram enormemente as elites chinesas com os seus conhecimentos em ciência e tecnologia e com os seus talentos para a pintura e a música. Além de cumprirem com os seus deveres religiosos, os missionários se ocupavam em aprender chinês, fazer observações astronômicas, trabalhar em projetos de geografia e cartografia e empreender cálculos matemáticos. Em vários sentidos, funcionaram bem como intermediários entre as civilizações européia e chinesa, introduzindo na China os ensinamentos do Ocidente cristão e levando para a Europa o saber e os clássicos chineses. Assim, estabeleceu-se, pela primeira vez na história, de forma intensa e efetiva, um exemplo de intercâmbio de comunicação e diálogo entre o Ocidente e o Oriente. Os missionários cristãos que estiveram na China aproveitaram para difundir a sua mensagem acerca de Deus, dos mandamentos, da boa nova, para ampliar o alcance da doutrina cristã e produzir obras que visavam, especificamente, esclarecer os equívocos dos povos chineses sobre o cristianismo e propagar os ensinamentos da fé cristã adaptados ao pensamento chinês. Muitos dos jesuítas eruditos que estiveram na China, ao retornarem à Europa, apresentaram sua nova visão da sociedade que conheceram, elaborada a partir do contato que tiveram com aquela cultura e que, no entanto, a Igreja se lhes opunha (Ibidem).

Sanjay Subhramanian, historiador indiano da atualidade, reuniu, em sua 
obra, boa parte do que até hoje se produziu sobre os contatos culturais e as transculturações que permearam as relações entre a Índia Colonial e o Império Ultramarino Português. ${ }^{6}$ Por opção, entretanto, dado o tempo ocupado pelas oficinas e as necessárias alternativas que se faziam prementes, não nos aprofundamos demasiadamente no estudo dos contatos entre Índia e Ocidente, preferindo, de outro lado, enfocar as trocas transculturais entre os mestres budistas e marciais da China e do mundo Hindu, a partir das reflexões sobre as viagens de mestres Chan/Zen, que foram tema de um subcapítulo de Entre o Kati e o Nirvana... Por fim, cabe lembrar que Jay Sakashita, historiador das religiões japonesas, contribuiu de forma significativa para o acréscimo da discussão em torno da história Cultural Japonesa.

\section{Itinerários de uma pesquisa}

Com relação aos encaminhamentos de caráter metodológico, delimitamos para este estudo a produção de manuais didáticos que abordem os temas relacionados com a história da China, da Índia e do Japão, sociedades que mais se destacam em se tratando de história do Oriente Distante e que são pouco exploradas nas salas de aula das escolas do Ensino Médio, por conta dos problemas por nós já explicitados.

Partimos, inicialmente, do diálogo com os professores de historia da Escola Estadual da Prata. Realizamos diversas entrevistas e analisamos as abordagens trazidas pelos autores de livros didáticos utilizados em sala de aula, como forma de elaborar um primeiro diagnóstico sobre a ocorrência -ou, na maioria dos casos, a ausência- dos conteúdos didáticos relativos à história do Oriente Distante.

Simultaneamente à execução dessas atividades, também teve lugar uma revisão bibliográfica nas matrizes da historiografia atual sobre o Oriente Distante, seja nas vertentes de uma nova e revolucionária História Política, seja nos domínios da Nova História Cultural, ou ainda, nos meandros da Historiografia Ambiental, possibilidades distintas, que foram evocadas com o intuito de realçar questões pertinentes ao trabalho.

\footnotetext{
6 Vide Conferência de Sanjay Subrahmanyan, integrada na Conferência internacional sobre "The Self and the Other", Institute of Romance Studies, Universidade de Londres, Março de 1997. Veja-se também: Luís de Sousa Rebelo (1998) e Sanjay Subrahmanyam (1998).
} 
A aproximação entre Universidade e escola se deu através da realização de reuniões periódicas com Grupo de pesquisa Japão, China e Índia: a história das relações entre o Oriente Distante e o Império Ultramarino Português, que contou com participação de professores de ambas as instituições. Tais encontros permitiram as discussões, parcerias para pesquisa e para elaboração de estratégias de ensino para serem aplicadas aos alunos da escola. Ao longo da elaboração do material didático, foram realizadas leituras e discussões historiográficas pertinentes às temáticas relativas às sociedades e culturas em pauta, para que nos pudéssemos munir do devido suporte teórico-metodológico.

A presença na bibliografia citada de textos estrangeiros se justifica pela relativa carência de referências atualizadas em idioma português. Essa ausência, entretanto, ajuda a salientar a necessidade de se traduzirem obras e de se produzirem manuais didáticos destinados a um público de professores e alunos não familiarizados com os idiomas francês e inglês. Nos debates e cursos de extensão que se pretende realizar, textos traduzidos serão trazidos à baila e sínteses didáticas, surgidas de um atento ouvir das necessidades e curiosidades locais, serão, gradativamente, elaboradas.

Quanto às obras traduzidas para o português, cabe salientar que o relativo "hermetismo" de sua linguagem, presa a um excessivo preciosismo de tradução, acaba por dificultar sua leitura direta por parte do público interessado. Partimos, aqui, da premissa de que ofício do historiador é marcado por uma necessidade de diálogo. Nós escrevemos, freqüentemente, sobre o que, do passado, permanece presente, sobre as interrogações que, a partir de nossos dias e de suas questões, dirigimos aos mortos. Para tanto, devemos, acima de tudo, nos fazer entender, para que a história não fique restrita aos muros da academia.

Uma vez concluída a pesquisa e elaboração do material didático pertinente a história de cada uma das culturas aqui enfocadas, foi o momento de preparação para a execução da oficina temática em sala de aula juntamente com o professor da turma. O projeto foi aplicado na juntamente a alunos diurnos das turmas da $1 .^{\mathrm{a}}$ série do ensino médio.

Uma vez concluída a oficina, foi o momento de analisarmos a experiência realizada em sala de aula, apontando desafios, propondo alternativas e aprimorando uma metodologia passível de utilização na prática cotidiana do ensino de 
história. Assim, buscando contribuir para a superação de um permanente desafio que se impõe nos níveis de ensino fundamental e médio: o fato de a prática pedagógica freqüentemente está dissociada/desvinculada da pesquisa.

Para aplicar os resultados obtidos durante a execução da pesquisa, buscamos ainda a realização de cursos de capacitação com os professores das escolas públicas do Ensino Médio de Campina Grande, com vistas em apontar novos conteúdos, estratégias e metodologias passíveis de serem trabalhadas em sala de aula.

Este projeto abrirá possibilidades para que alunos de escolas públicas do ensino médio disponham de recursos didáticos e metodológicos aprimorados e menos enfadonhos; para que os professores de escolas públicas melhorem a sua prática docente através dos estudos e experiências realizadas; e, por fim, para que os alunos e professores de graduação envolvidos no projeto cresçam com as discussões teórico-metodológicas acerca do prazer, dos desafios e das dificuldades pertinentes à prática docente do ensino de história.

\section{Uma experiência de pesquisa}

A pesquisa, o estudo e o ensino-aprendizagem de história das sociedades orientais nas escolas de ensino básico têm-se constituído em um desafio para professores e alunos, principalmente quando se trata da rede pública de ensino, onde as dificuldades são ainda mais acentuadas.

Como a nossa problemática, conforme explicitamos acima, diz respeito ao ensino de história do Oriente Distante no Ensino Médio das escolas públicas, partimos de um diálogo com alguns professores da instituição para sabermos a forma como têm trabalhado os conteúdos relativos a essas sociedades com os seus alunos, bem como, quais são os desafios apontados, os limites e as possibilidades que enfrentam cotidianamente em sala de aula.

Realizado entrevistas com os professores sobre o ensino de história das sociedades orientais, especificamente, da China, da Índia e do Japão, compreendemos que um dos motivos que os limitam é a escassez de material didático que abordem esses temas, conforme nos relatou a professora M.7, que

\footnotetext{
7 A partir dessa referência, optamos por identificar os depoimentos dos entrevistados através da utilização de letras com vista em não expor a opinião emitida por esses profissionais.
} 
ministra aulas de história no Ensino Médio há 22 anos:

Eu já cheguei a trabalhar a história das sociedades do oriente em sala de aula, mas isso, veja em, no final do ano, quando dar tempo, geralmente não dá, já trabalhei China, Índia e Japão somente pela curiosidade que os meus alunos tinham. Trabalhei com os programas do TELECURSO 2000, porque é mais didático, mostra a forma como esses povos se vestem, seus ritos e sua cultura, acho que é muito mais didático do que os livros. Não agüento mais trabalhar com livro didático! É muito difícil! Só agora que o Oriente está em evidência, a universidade quer que a gente trabalhe. Eu acho que a universidade tem que repensar juntamente conosco como trabalhar com os nossos alunos de uma forma diferente. Precisamos ser ensinados. Tratar do oriente em sala de aula, não há recursos, não sabemos como, e o livro didático é muito pouco. ${ }^{8}$

Não obstante a importância, na atualidade, de que os alunos conheçam a história da China, da Índia e do Japão, através desse depoimento percebemos as dificuldades que o professor encontra no dia a dia da sala de aula para abordar os temas relativos a essas sociedades, o que acaba relegado-as a uma posição secundária no currículo escolar.

Convém ressaltar, no entanto, que, além de os livros didáticos abordarem superficialmente e com muitas lacunas a sociedade, a cultura e a história dos povos orientais, os professores afirmam que, apesar dessas limitações, muitos autores já discutem essas temáticas e que, além disso, é possível ainda buscar informações em outras fontes, entretanto, a razão que os impedem de trabalhar esses temas na aula de história, é porque eles não constam nos programas de vestibulares das universidades paraibanas, conforme observamos o depoimento da professora M.:

Não abordamos estas sociedades simplesmente porque não está no programa do vestibular, então por isso não entra. A questão não é tanto os livros didáticos, pois a maioria já trás algumas coisas sobre esse tema, mas o problema é o programa de vestibular que não exige. Já que somos "obrigados", a palavra é essa mesma, a seguir rigorosamente os conteúdos que caem no vestibular. Os alunos só querem ver assuntos que estão nos programas de vestibulares.

O Professor E. reitera esses argumentos afirmando que a ausência desses conteúdos nas escolas do Ensino Médio é justificada tanto pelos silêncios dos manuais didáticos quanto por não fazer parte dos programas de vestibulares:

\footnotetext{
Eu não trabalho a história das sociedades chinesa, indiana e japonesa, apenas organizo um "organograma” com todas as civilizações: egípcia, mesopotâmica, suméria, etc., os chamados estados teocráticos, e mostro tudo de uma vez, seus aspectos políticos, sociais, econômicos e culturais, destacando o fato de que todas elas só diferem quanto à economia e à cultura. Os motivos porque não trabalhamos a história
}

8 Entrevista realizada em junho de 2007. 
da China, Índia e Japão em sala de aula são simples: não consta no programa de vestibular e também os conteúdos presentes nos livros didáticos são mínimos. É somente isso (Grifos nossos).

Constatamos, assim, com base nas entrevistas realizadas, que a ausência de abordagens mais amplas e aprofundadas por parte dos autores de manuais didáticos de historia, bem como, a pouca relevância que as comissões de vestibulares têm dado a esses temas, esta talvez como conseqüência da primeira, sejam os principais responsáveis por essas lacunas nos currículos de história do ensino básico. Entretanto, alguns professores ainda apontaram outros motivos. É o caso da Professora S., que atua no ensino de história há 19 anos que nos relatou:

\begin{abstract}
Reconhecemos que ainda existem alguns limites para se trabalhar as sociedades orientais em sala de aula, inclusive livros de "grandes" autores mal fazem referência ao Leste europeu, ao Oriente Médio e Distante. Os livros didáticos são muito limitados. Além dos problemas dos livros, também não há estrutura para trabalharmos com outros recursos. Não temos uma sala de vídeo bem estruturada para se trabalhar com filmes, há dificuldades para trabalharmos com música em sala de aula. Nossa carga horária é imensa, não temos tempo para prepararmos aulas com outras linguagens. Existem dificuldades para buscarmos outras fontes além do livro didático para enriquecermos a aula. Existem jornais, revistas, filmes que podem ser inseridos no contexto histórico e preencher a lacuna dos livros didáticos, mas são muitas as dificuldades que nós que atuamos em escolas públicas enfrentamos em nosso cotidiano.
\end{abstract}

A partir da elaboração desse diagnóstico sobre a ocorrência dos temas de história Oriental nos conteúdos programáticos do Ensino Médio Estadual em Campina Grande, bem como, dos limites que impedem que os alunos e professores tenham acesso a esses conteúdos, é possível perceber a necessidade de que estes sejam revistos, que os professores de história estejam aptos a ensinar temas relacionados à cultura, à política e à sociedade de cada um desses países.

Propusemo-nos então, a partir dessa constatação, contribuir para a pesquisa, o ensino e a aprendizagem de história da China, da índia e do Japão. $\mathrm{O}$ enfoque foi dado à pesquisa prévia sobre a história dessas sociedades, à realização de oficinas para discussão e produção de textos com os professores de história da escola estadual da Prata e à produção de material didático a ser utilizado pelos professores, conforme explicitaremos a seguir:

Desde junho de 2007, os membros do grupo de estudos em História Oriental reunia-se, quinzenalmente, para promover a leitura comentada dos clássicos da historiografia sobre o Japão, a China e a Índia. O Grupo de estudos 
era freqüentado por professores de história do Ensino Médio de colégios estaduais de Campina Grande, especialmente do Estadual da Prata, local onde são realizadas as reuniões, e por alunos da graduação e docentes da UFCG. Este grupo manifestou considerável interesse em desenvolver uma parceria didática com a Unidade Acadêmica de História e Geografia e foram receptivos às nossas sugestões, propiciando um interessante intercâmbio, trocas de experiências e diálogos entre a teoria e a prática do ensino de história.

Não obstante os currículos dos cursos de historia das universidades brasileiras ainda não reconheçam a importância do ensino da história dessas sociedades, ressaltamos que o nosso curso de graduação oferece, atualmente, três disciplinas que enfocam estudos orientais, quais sejam: História Antiga Oriental, História Medieval Oriental, História Moderna Oriental. Observamos que a ausência de referência mais atenta a esses temas nos cursos de Ensino Médio, na cidade de Campina Grande, não se deve, em absoluto, à sua irrelevância histórica e geopolítica, mas, primordialmente, à escassez de material didático acessível e conhecimentos a respeito por parte dos professores.

A etapa seguinte do projeto diz respeito à elaboração de livros didáticos elaborado pelos professores e alunos, especialmente para a temática da história do Oriente Distante, resultando dessa parceria e das discussões encetadas em torno dos livros didáticos, do currículo, dos conteúdos, das experiências desenvolvidas através das oficinas.

Uma das contribuições diz respeito ao, já mencionado, paradidático Entre o Kati e o Nirvana: budismo, arte marcial e ascese em uma breve história das técnicas marciais do Mosteiro de Shaolin (Séculos XVI a XIX), e trata-se de um texto agradável e didático, cujo maior mérito consiste em sintetizar parte das contribuições historiográficas sobre a história da China, das artes marciais e da cultura dessa sociedade, que somente poderia ser acessado através dos idiomas inglês e francês.

No que se refere à participação dos membros do grupo de estudos orientais, editamos uma coletânea de textos didáticos produzidos pelos alunos e covidados com objetivo de suprir a carência de material didático nas escolas de ensino médio sobre história da China, Índia e Japão. Entre os temas trabalhados, destacamos: "Pelas sobrancelhas de Pai-me!": Uma leitura de 
elementos da história marcial chinesa a partir dos filmes de kung-fu, que versa a marcialidade chinesa a partir de elementos colhidos junto ao chamado "cinema marcial chinês", entendido como fonte importante de conteúdos nãocorporais para praticantes de Kung-Fu em um país como o Brasil; em seguida, Uma breve história da produção cinematográfica chinesa, que consiste em uma pesquisa que explicita uma breve história da trajetória do cinema chinês, apresentando o contexto histórico em que a indústria cinematográfica se desenvolveu na China e sua externização para o público internacional, sendo o cinema um instrumento de difusão da cultura, política, sociedade, hábitos, mentalidades e história de um povo; em terceiro lugar, o artigo Filosofia, natureza e história: A China ideal em Voltaire na construção de uma crítica à Europa cristã setecentista, que constitui uma análise critica de como os filósofo do Iluminismo, sob o olhar imperialista ocidental, constrói a imagem de um Oriente com uma cultura, uma sociedade e uma política ideal, para que, a partir daí, possa contestar valores arraigados no pensamento cristão ocidental; e, ainda, o artigo intitulado Luzes e sombras de um Oriente "Próximo": o olhar Ocidental na historiografia moderna, que se debruça de forma mais específica no olhar do filósofo Montesquieu.

Simultaneamente à elaboração dessas propostas didáticas, realizamos as oficinas temáticas para os alunos da primeira série do Ensino Médio da escola selecionada como objeto de nossa análise e diálogo. Através das quatro realizadas ao longo do semestre, tivemos a oportunidade de experimentar, juntamente com os professores da escola, diversas modalidades e estratégias didáticas para o enriquecimento do ensino de história do Oriente. Entre os temas enfocados em relação às peculiaridades culturais da China, da Índia e do Japão, destacamos: Natureza, Sociedade, Cultura, Cotidiano, Sexualidade, Gênero, Economia, Alimentação, História, Arquitetura, etc.

Uma vez diagnosticado a prática do ensino de história do Oriente nas escolas públicas estaduais de Campina Grande, percebemos que são muitos os embates e dilaceramentos que permeiam a prática cotidiana de professores e que os impedem de realizar um ensino de história mais prazeroso e conseqüente, menos tradicional e mais comprometido com as mudanças ocorridas na sociedade de nosso tempo. Constatamos que as lacunas dos livros didáticos, a imensa carga horária de trabalho que o professor assume 
diariamente, bem como, a falta de estrutura física adequada para que possa planejar e desenvolver seu trabalho, impedem-nos de buscar outras linguagens, estratégias e metodologias que contribuam para a melhoria do ensino e da aprendizagem de história por parte dos alunos de escolas públicas.

A receptividade da direção da escola, dos alunos e dos professores em relação ao nosso trabalho, explica, em parte, que a formação continuada do professor de história é marcada por dificuldades múltiplas que os impedem de acompanhar as mudanças tecnológicas, sociais e teórico-metodológicas do ensino de história. Os alunos, também atingidos por tais reflexos, na sua condição de receptáculos de informações, conteúdos, currículos, livros e materiais didáticos, freqüentemente, buscam um ensino de história mais prazeroso e condizente com a sua realidade cotidiana e que responda a parte de suas indagações e curiosidades.

Nesse sentido, atentar para as especificidades historiográficas e para o estudo, o ensino e a aprendizagem de histórias de sociedades que ocupam hoje posição relevante no cenário mundial, como é o caso da China, da Índia e do Japão, significa atender a essas demandas dos alunos e das novas gerações que passam pelas salas de aula do Ensino Médio com objetivos que, em geral, podem ir além de adquirir meras e simplistas informações para aprovação no vestibular. A proposta seria um ensino de história para a vida, para o presente e que supere todas essas dificuldades.

Destacamos aqui a importância de se elaborar um material didáticopedagógico em parceria com os próprios professores das escolas públicas do Ensino Médio, uma vez que esse diálogo possibilitou atingir diretamente à realidade estrutural e social dos alunos e da escola em geral. Permitiu-nos, também, enquanto pesquisadores da área, autores de livros didáticos e paradidáticos de história, pensarmos nas múltiplas possibilidades de ampliarmos as perspectivas do ensino de história nas escolas públicas, na tentativa de superar os obstáculos e as dificuldades que, em geral, os docentes dessas instituições enfrentam em seu cotidiano.

\section{Novas propostas para o ensino de História do Oriente}

Constatamos, ao longo do desenvolvimento deste trabalho, que não 
obstante a importância que as sociedades e as culturas milenarmente reelaboradas na região do Oriente Distante apresentam para o patrimônio histórico-cultural da humanidade, especialmente, o papel que tais sociedades exercem no cenário econômico e político da atualidade, muitas universidades brasileiras e, principalmente, escolas de Ensino Básico têm-se confrontado com lacunas e desafios no que tange ao ensino da história dos seus costumes, modos de vida, tradições, economias, organização política, meio ambiente, etc. e de sua influência sobre a herança cultural do Império Ultramarino Português.

No caso da Escola Estadual da Prata, ambiente no qual realizamos pesquisas e experiências sobre o ensino de história do Oriente, observamos que a abordagem dos temas relacionados à história da China, da Índia e do Japão nos conteúdos programáticos dessa escola são ainda muito incipientes, em virtude de um conjunto de fatores que se entrecruzam na prática cotidiana que se interioriza nessa cultura escolar: programa de vestibulares que não enfatizam tais questões, lacunas na formação dos professores, ensino tradicional de história que carece de novos subsídios para viabilizar práticas pedagógicas e a utilização de recursos didáticos renovados, incentivo à vinculação, desde a escola básica, entre ensino, pesquisa e extensão, problematização e análise conjunta dos livros didáticos utilizados pelos docentes em geral como a principal ferramenta metodológica, etc.

Nesse quadro de referências, especialmente, diante da notória lacuna dos manuais didáticos que tratam dos temas relacionados à História oriental, observamos a necessidade de que o professor não se paute exclusivamente nessa ferramenta para o ensino de história, uma vez que é possível desenvolver novas alternativas que facilitem o ensino-aprendizagem e que o façam de forma consequente e diferenciada, ou seja, trazendo à baila, para o palco da sala de aula, cores e luzes que tornem resplandecentes o espetáculo do ser professor. Referimo-nos a um espetáculo não por assumirmos uma visão utópica em relação ao ensino público, ao contrário, contatarmos parte dessa realidade e ainda assim acreditarmos que a profissão professor, apesar das dificuldades que lhe é inerente em qualquer instituição de ensino, pode ser realizada com brilho e entusiasmo, quando feita com apreço e com a perspicácia de buscar soluções para superar desafios.

No caso do ensino de história do Oriente na escola pública onde 
realizamos a pesquisa, buscamos enfatizar a necessidade de explorar determinados subsídios que nos são diariamente acessíveis e que podem dinamizar a prática cotidiana dos alunos e professores, quais sejam, filmes, músicas, histórias em quadrinhos, animações, alimentação, poesias, romances, maquetes, imagens e fotografias, charges, etc. Para tanto, o planejamento da aula, as trocas, a pesquisa e a preparação dos recursos emergem como pressupostos de fundamental importância para obter êxito em sala de aula e estimular os alunos à curiosidade pela pesquisa.

Além dos problemas relacionados aos materiais didáticos disponíveis, a evidência de que os programas de vestibulares não têm acompanhado a relevância que essas sociedades assumiram na atualidade -o que denota que as próprias universidades que selecionam os alunos ingressantes na instituição não têm atentando para tais questões- não deve ser pré-requisito para impedir que a história das sociedades do Oriente Distante seja pauta de aulas e temas de pesquisa no Ensino Médio e que os alunos adquiram pelo menos uma parcela de informações e conhecimentos sobre tais temáticas. O que se tem observado é que a mídia em geral tem exercido esse papel de (in)formar a sociedade a respeito da história do Oriente, o que tem acarretado a perpetuação de uma série de preconceitos e estereótipos frequentemente pautado pelos veículos de comunicação. Nesse sentido, enquanto não é a escola que sistematiza as informações sobre as sociedades orientais, a mídia, em geral, desfigura o sentido que cada universo cultural possui, seja em relação à Índia, à China ou ao Japão.

Evidencia-se que o nosso esforço em contribuir, através de uma parceria entre a Unidade Acadêmica de História e Geografia da UFCG e a Escola Estadual, para a elaboração de material didático alternativo e acessível para o ensino de História do Oriente Distante surtiu importantes efeitos, uma vez que, além de trabalhamos e dialogamos diretamente com alunos e professores da escola, os nossos objetivos foram materializados através da edição do material didático-pedagógico relativo à história do Oriente e da sua aplicação em sala de aula juntamente com os professores e alunos. Nossa proposta foi colaborar no sentido de promover uma aproximação entre os estudos acadêmicos e os conteúdos didáticos do Ensino Médio das escolas estaduais, a partir, obviamente, da valorização da experiência cotidiana e dos saberes adquiridos 
pelos alunos e pelos professores. Não obstante, são muitos os desafios que ainda se impõem aos alunos e professores de ambas as instituições na busca pela melhoria da qualidade do ensino básico.

O grupo de estudos orientais, cujas reuniões foram realizadas na própria Escola Estadual da Prata, com o intuito de atrair os professores para as discussões, o material didático produzido a partir de traduções de textos em inglês e francês, com linguagem acessível e agradável, constituem-se como um instrumento de caráter didático que diminui parte da escassez bibliográfica acerca da história do Oriente Distante; além disso, a coletânea de textos sobre temas os mais diversos relativos à história daquelas sociedades, os ciclos de debates que realizamos juntamente com os professores da escola, são algumas das formas, estratégias e metodologias que encontramos para contribuir para a diminuição dos silêncios e das lacunas que permeiam os manuais didáticos disponíveis.

O trabalho com os professores do Ensino Médio das escolas estaduais de Campina Grande foi fundamental para percebermos quanto ainda existem disparidades e distâncias entre o conhecimento produzido na universidade e a realidade do ensino de história nas escolas de ensino básico. São muitos os desafios impostos, cotidianamente, à direção da escola, aos professores e aos alunos, e somente através da ampliação de parcerias dessa natureza, do diálogo entre escolas e universidades, considerando a rotina de trabalho dos docentes, torna-se possível amenizá-los.

A intenção seria, de forma mais modesta, experienciar a possibilidade de revirar essa terceira margem do Oriente, que há tanto foi tratada pelos historiadores ocidentais de forma etnocêntrica, sem um olhar atento à alteridade e às especificidades histórico-culturais seja em relação à China, à Índia ou ao Japão.

Pudemos refletir também sobre o nosso papel e sobre os nossos desafios enquanto alunos, pesquisadores e/ou professores universitários que trabalham na formação dos professores que irão, durante e após concluírem o curso de graduação, atuar no ensino de História nas escolas públicas. Com base nessa pesquisa, podemos perceber que é possível socializar os conhecimentos elaborados nas universidades públicas e contribuir para a ampliação das possibilidades de abordagens historiográficas relativas as diversas sociedades que exerceram e 
ainda exercem importantes papéis no cenário mundial da atualidade.

\section{Bibliografia}

AGUIAR, José Otávio. Entre o Kati e o Nirvana: budismo, arte marcial e ascese em uma breve história das técnicas marciais do Mosteiro de Shaolin (Séculos XVI a XIX). Campina Grande, PB: EDUFCG, 2008.

APOLLONI, Rodrigo Wolff. Shaolin à brasileira: estudo sobre a presença e a transformação de elementos religiosos orientais no Kung fu praticado no Brasil. Pontifícia Universidade Católica de São Paulo: São Paulo, 2004 (Dissertação de Mestrado).

. "Pelas sobrancelhas de Pai-mei!": Uma leitura de elementos da história marcial chinesa a partir dos filmes de kung-fu. IN: AGUIAR, José Otávio. História do Oriente. Campina Grande, PB: EDUFCG, 2008, pp. 4-22.

BENEDICT, Ruth. O crisântemo e a espada. São Paulo: Papirus, 1999.

BLANCO, Lucien. Ásia Contemporânea. Madri: Siglo XXI Editores, História Universal Siglo XXI, 1976.

BRASÃO, Eduardo. Apontamentos para a história das relações diplomáticas de Portugal com a China: 1516-1753. Lisboa: Ag. Geral das Colônias. Divisão de Publicações e Biblioteca, 1949.

BRAUDEL, Fernand. As civilizações nem sempre dizem não; O capitalismo fora da Europa. IN: Civilização material, economia e capitalismo: séculos XVXVIII. Tradução Telma Costa. São Paulo: Martins Fontes, 1996.

BROWN, Joe David. Índia. Nova Iorque: Time Incorporated, 1961.

BURITI, Catarina de Oliveira; AGUIAR, José Otávio. Filosofia, natureza e história: A China ideal em Voltaire na construção de uma crítica à Europa cristã setecentista. IN: AGUIAR, José Otávio. História do Oriente. Campina Grande, PB: EDUFCG, 2008, pp. 44-57.

CALDEIRA, Carlos José. Apontamentos d'uma viagem de Lisboa á China e da China a Lisboa. Lisboa: Typographia de Castro \& Irmão, 1853.

DERRICKSON, Carol. M. Chinese for the Martial Arts. $1^{\text {a }}$ edição. Rutland: Charles E. Tuttle, 1996.

GRANET, Marcel. O Pensamento Chinês. São Paulo: Cia das Letras, 1998. . A Civilização Chinesa. Rio de Janeiro: Ferni, 1979.

HUNT, Leon. Kung Fu Cult Masters - From Bruce Lee to Crouching Tiger. Londres, New York: Wallflower Press, 2003.

INGRAM, Paul. Budismo-Japão. IN: BOWKER, John (org.). O livro de ouro das religiões. Rio de Janeiro: Ediouro, 2004.

KURE, Mitsuo. Samurai: an illustrated history. Boston: Tuttle publishing, 2002.

MEIRA, Jean Paul Gouveia. Luzes e sombras de um Oriente "Próximo": o olhar Ocidental na historiografia moderna. IN: AGUIAR, José Otávio. História do Oriente. Campina Grande, PB: EDUFCG, 2008, pp. 58-64. 
NOVAIS, Adauto (Org). A Outra Margem do Ocidente. São Paulo: Companhia das Letras, 1999.

NAPOLITANO, Marcos. Fontes audiovisuais: a história depois do papel. IN: PINSKY, Carla Bassanezi (org.). Fontes históricas. São Paulo: Contexto, 2005.

REBELO, Luís de Souza. As Crónicas Portuguesas do Século XVI. IN: GIL, Fernando Gil e MACEDO, Helder. Viagens do Olhar. Porto: Campo das Letras, 1998, pp. 175-201.

SAHLINS, Marshal. Ilhas de História. Rio de Janeiro: Jorge Zahar, 1999.

SAID, Edward. Orientalismo: o Oriente como invenção do Ocidente. São Paulo: Companhia das Letras, 1989.

SAKASHITA, Jay. Religiões japonesas. IN: BOWKER, John (org.). O livro de ouro das religiões. Rio de Janeiro: Ediouro, 2004.

SCHMIDT, Maria Auxiliadora. A formação do professor de história e o cotidiano da sala de aula. IN: BITTENCOURT, Circe (Org.). O saber histórico na sala de aula. São Paulo: Contexto, 1998.

SILVA, Gustavo Henrique. Entre o fuzil e a Katana: Nathan Algren, Saigo Takamori e a construção do discurso sobre a alteridade em $O$ Último Samurai. IN: AGUIAR, José Otávio. História do Oriente. Campina Grande, PB: EDUFCG, 2008, pp. 23-28.

SPENCE, Jonathan. D. Emperor of China: self-portrait of K'ang-shi. New York: Vintage Books, 1998.

. Em busca da China moderna: quatro séculos de história. São Paulo: Companhia das Letras, 1996.

SUBRAHMANYAN, Sanjay. Conferência de integrada na Conferência internacional sobre "The Self and the Other", Institute of Romance Studies, Universidade de Londres, março de 1997.

. The career and legend of Vasco da Gama. Cambridge: Cambridge University Press, 1997. Tradução portuguesa, A carreira e lenda de Vasco da Gama, pref. de Luís Filipe Thomaz. Lisboa: Comissão Nacional para as Comemorações dos Descobrimentos Portugueses, 1998.

VAN HAANDEL, Fabiana P. V.; VAN HAANDEL, Johan C. Uma breve história da produção cinematográfica chinesa. IN: AGUIAR, José Otávio. História do Oriente. Campina Grande, PB: EDUFCG, 2008, pp. 29-45

YAO, Xinzhong. Religiões chinesas. IN: BOWKER, John. O livro de ouro das religiões: da pré-história aos nossos dias. Rio de Janeiro: Ediouro, 2004, pp. 210-253.

YUKIO, Kaibara. Historia del Japón. México: Fondo de Cultura Econômica, 2000.

Colaboração recebida em 03/03/2009 e aprovada em 15/06/2009. 